\title{
Meta-análise de estudos sobre o efeito do fogo nos biomas florestais em relação aos microrganismos fúngicos \\ Francisca de Cássia Silva da Silva $\odot^{1^{*}}$ Augustus Caeser Frank Portella ${ }^{1}$ Marcos Giongo ${ }^{1}$
}

${ }^{1}$ Universidade Federal do Tocantins, Programa de Pós-graduação em Ciências Florestais e Ambientais, Campus Universitário de Gurupi, Rua Badejos chácara 69,72 Lt 07, Zona Rural 77404-970 - Gurupi, TO, Brasil.

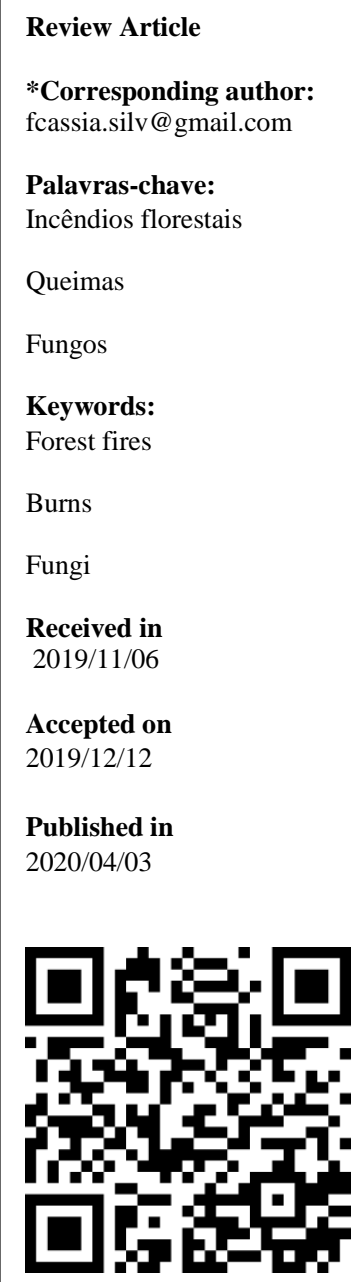

DOI:http://dx.doi.org/10.340 62/afs.v7i1.9339

\section{(cc) BY}

RESUMO: O fogo é um elemento da mudança global que pode influenciar as comunidades fúngicas, com intuito de compreender como o fogo influência essas comunidades, foi realizado uma revisão sistemática com meta-análise de 30 estudos que abordassem o tema respostas fúngicas ao fogo. Dos estudos avaliados $56,67 \%$ obtiveram resultados positivos para o uso do fogo em função da comunidade fúngica e 43,33\% apresentaram efeitos negativos, 56,66\% das análises dos microrganismos fúngicos foram realizadas através da coleta do solo. As respostas dos microrganismos fúngicos ao fogo diferiram significativamente entre os tipos de vegetação, a biomassa fúngica aumentou após incêndios em Florestas boreais, mas não após incêndios em Florestas temperadas e tropicais, a Floresta tropical não apresentou diferenças entre os incêndios florestais e queima prescrita. Foi verificado nesta meta-análise que os incêndios florestais levam a uma maior redução da comunidade fúngica do que as queimadas prescritas. Os mecanismos ou processos responsáveis pela diversidade de espécies de fungos após o uso do fogo tanto para incêndios como queima prescrita permanecem desconhecidos. Desta forma a padronização das metodologias é necessária para que se possa realizar comparações entre os estudos da mesma tipologia de vegetação.

\section{Meta-analysis of studies on the effect of fire on forest biomes in relation to fungal microorganisms}

\begin{abstract}
Fire is an element of global change that can influence fungal communities, thus participating in the dynamics of ecosystems. In order to understand how fire influences these communities, a meta-analysis of 30 fungal responses published to fire was carried out. From the studied studies 56,67\% obtained positive results for the use of fire as a function of the fungal community and $43,33 \%$ presented negative effects, $56,66 \%$ of the analysis of the fungal microorganisms was done through the collection of the soil. The responses of fungal microorganisms to fire differed significantly between vegetation types and fungal biomass increased after fires in boreal forests, but not after fires in temperate and tropical forests, the tropical forest did not present differences between forest fires and prescribed burning. It was verified in this meta-analysis that the forest fires lead to a greater reduction of the fungal community than the prescribed fires. The mechanisms or processes responsible for the diversity of fungal species after the use of fire for both fire and prescribed burning remain unknown. In this way the standardization of methodologies is necessary so that comparisons can be made between the studies of the same typology of vegetation.
\end{abstract}




\section{Introdução}

Os microrganismos presentes no solo e na serapilheira desempenham um papel importante nos ecossistemas terrestres, atuando na transferência de carbono dos ecossistemas para a atmosfera, através da decomposição da matéria orgânica. Esses microrganismos são sensíveis as mudanças globais, incluindo as mudanças na temperatura, quantidade de nutrientes no solo e a disponibilidade de umidade. O fogo é um aspecto relevante quando se trata de mudanças climáticas, podendo ocasionar prejuízos as comunidades microbianas do solo, tendo em vista que a ação da chama reduz a quantidade da matéria orgânica que é a fonte inicial de energia dos microrganismos (Fuentes-Ramirez et al., 2018; Hawkes et al., 2011).

Os incêndios florestais atingem drasticamente os ecossistemas naturais, há uma previsão que a ocorrência e intensidade dos incêndios florestais aumentem nos biomas florestais (Pechony e Shindell, 2010). Esse aumento já é evidente nas florestas do oeste dos Estados Unidos (MILLER et al., 2009) especialmente boreais (Kasischke e Stocks, 2000). Os estudos voltados para averiguação de como o fogo afeta os microrganismos do solo se faz necessário para uma melhor compreensão da dinâmica do ecossistema sob as futuras mudanças globais.

Demoling et al. (2008) afirma que algumas espécies de fungos são sensíveis ao fogo e outras são adaptadas ao fogo ocorrendo abundantemente após incêndios. Assim, mudanças na abundância de fungos no solo após uso do fogo permanecem incertas, se fazendo necessário a realização de mais estudos sobre o tema nos diversos ecossistemas florestais, tendo em vista que os fungos são importantes decompositores é que as mudanças ocasionadas pelo fogo podem afetar a ciclagem de nutrientes, comprometendo assim a dinâmica dos ecossistemas.

Mudanças pós-fogo nas propriedades químicas e físicas do solo variam em sua duração e isso pode ter consequências para a recuperação da biomassa microbiana após os incêndios. Por exemplo, a rápida regeneração da vegetação adaptada ao fogo pode anular as mudanças na umidade do solo e na temperatura do solo nos primeiros anos após um incêndio como é o caso do bioma Cerrado (Claridge et al., 2009). Além disso, aumento na disponibilidade de $\mathrm{N}$ inorgânico podem ser limitados, onde as plantas e os micróbios do solo adaptados assimilam imediatamente esses nutrientes. Por outro lado, a volatilização de nutrientes durante incêndios pode ocasionar a redução de nitrogênio em um ecossistema por décadas (Harden et al., 2003; Benjamin et al., 2018). A matéria orgânica oriunda da serapilheira é afetada após incêndios intensos que consomem a maior parte do horizonte orgânico do solo (González-Pérez et al., 2004; Cairney et al., 2007).

Estudos obtiveram resultados favoráveis posteriores aos incêndios, apontando que as temperaturas elevadas promovem um crescimento de bactérias e fungos, especialmente nos ecossistemas em que a comunidade microbiana possui uma adaptação quanto a temperatura. Tendo em vista que a disponibilidade de $\mathrm{N}$ inorgânico no solo, aumenta as taxas de mineralização, promovendo um aumento de nutrientes e consequentemente estimulando o crescimento microbiano, além disso a redução da serapilheira acima do solo promove a evapotranspiração ocasionando aumento na umidade do solo (Demoling et al., 2008; Peay et al., 2009; Silvana et al., 2014).

Diversos estudos avaliaram as mudanças na abundância dos microrganismos após os incêndios, no entanto os resultados não são consistentes, divergindo na maioria das vezes, levando em consideração que alguns obtiveram como resposta o aumento e outros redução da abundância de microrganismos fúngicos. Neste sentindo o presente trabalho sintetizou a literatura existente sobre a dinâmica dos microrganismos fúngicos em relação ao fogo.

\section{Material e Métodos}

Levantamento bibliográfico e critérios de seleção

Uma revisão sistemática com enfoque meta analítico foi conduzida usando o banco de dados da ISI Web of Science com as palavras-chave: forest fires* ou fungi*. Os critérios de seleção utilizado foram:

-Tema: efeito do fogo nos microrganismos fúngicos. -Publicações a partir do ano 2000.

\section{Resultados}

Compilação dos dados

Atingindo os critérios pré-estabelecidos foram selecionados 30 artigos e registrado as seguintes informações:

-Ano de publicação;

-Nome da revista;

-País de estudo;

- Local da coleta da coleta;

-Metodologia utilizada [1 - Queima prescrita; 2 Incêndios Florestais];

- Tipo de Vegetação;

-Avaliação Fúngica [1 - Material vegetal; 2 - Solo; 3. Solo + Material vegetal];

-Avaliação do efeito do fogo [1 - Positivo; 2 Negativo];

-Período de estudo [1 - Longo; 2 - Curto].

$\mathrm{Na}$ figura 1 é possível verificar que no período estudado o número de publicações sobre o 
Silva et al.

tema foi crescente, com redução apenas no ano de 2015 e 2016, no entanto existe prospecção futura positiva.

Os Estados Unidos (EUA) obtiveram maior número de publicações sobre o tema comparado aos outros países avaliados como é possível verificar na figura 2 .

$\mathrm{Na}$ figura 3 estão descritas as revistas internacionais consultadas, podendo destacar a revista Forest Ecology and Management (For. Ecol.) com maior número de trabalhos sobre o tema. Esse periódico integra a ecologia florestal ao manejo florestal, com enfoque na aplicação do conhecimento biológico e social, tanto das florestas plantadas como das formações de vegetações naturais.

Figura 1. Número de artigos revisados em relação ao ano de publicação.

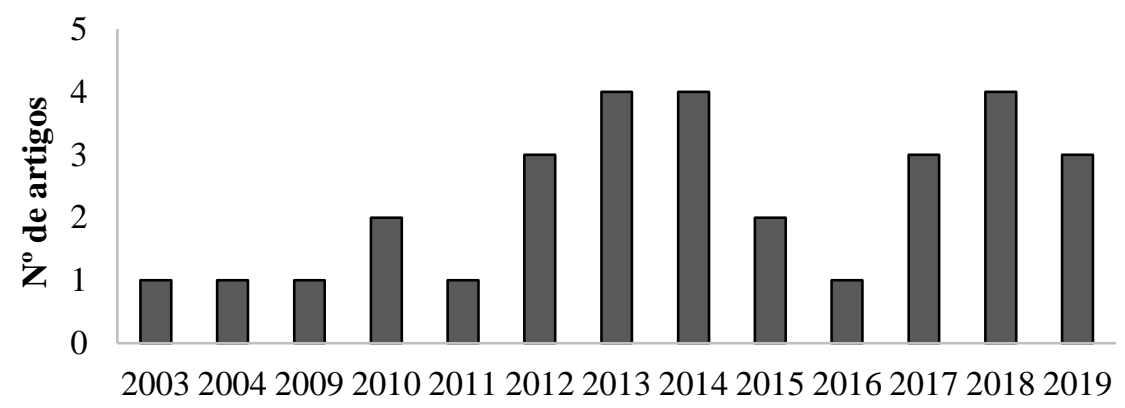

Ano

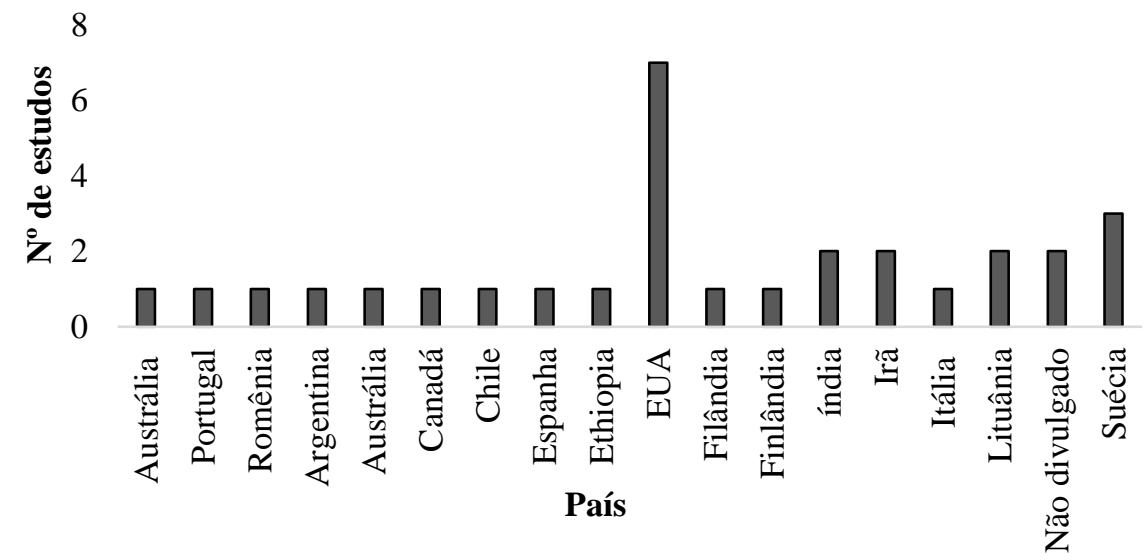

Figura 2. Países que foram realizados os estudos em relação ao número de estudos.

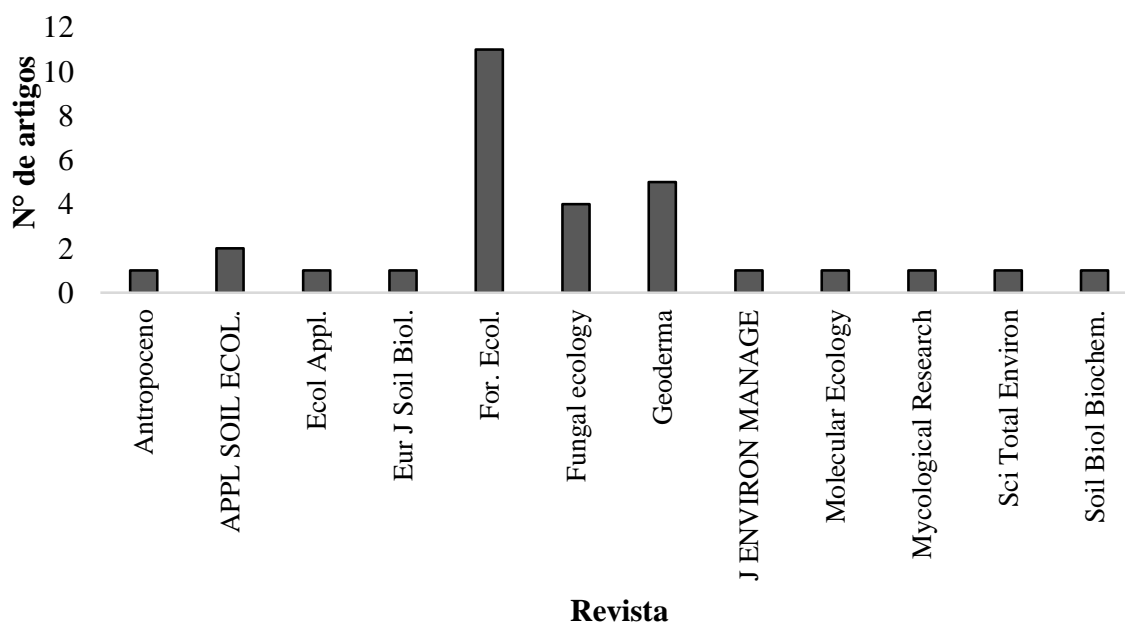


Figura 3. Número de artigos revisados em relação ao ano de publicação.

Na tabela 1 estão descritos o número de artigos para os efeitos, período de estudo e metodologia estudada e suas associações, desta forma $43,33 \%$ dos estudos apontaram um efeito negativo do fogo em relação aos microrganismos, no entanto a maioria dos artigos avaliados obtiveram resultado positivo com 56,67\%, apontando o aumento da diversidade de fungos após o uso do fogo. Quanto ao período de estudo avaliado, $80 \%$ apresentaram duração menor a 12 meses e apenas $20 \%$ artigos científicos foram resultados de pesquisas com tempo maior que um ano apontando a necessidade de maiores estudos a longo prazo para incêndios florestais, tendo em vista que os incêndios florestais afetam as comunidades fúngicas tanto a curto como a longo prazo.

Tabela 1. Relação do período de estudo com relação aos efeitos do fogo em função das metodologias utilizadas.

\begin{tabular}{lr}
\hline Efeito negativo & $\mathbf{1 3}$ \\
\hline Curto período de estudo & $\mathbf{1 2}$ \\
Incêndio florestal & 10 \\
Queima prescrita & 2 \\
Longo período de estudo & $\mathbf{1}$ \\
Incêndio florestal & 1 \\
\hline Efeito positivo & $\mathbf{1 7}$ \\
\hline Curto período de estudo & $\mathbf{1 2}$ \\
Incêndio florestal & 6 \\
Queima prescrita & 6 \\
Longo período de estudo & $\mathbf{5}$ \\
Incêndio florestal & 2 \\
Queima prescrita & 3 \\
\hline Total & $\mathbf{3 0}$ \\
\hline
\end{tabular}

Dos artigos revisados em sua metodologia para avaliar os efeitos do fogo em relação aos fungos, 56,66\% desses trabalhos realizaram suas análises por meio da coleta do solo, 33,34\% através da avaliação do material vegetal e somente $10 \%$ coletaram o solo e o material vegetal. Sabendo da importância da relação solo-planta dentro de um ecossistema, se faz necessário que mais estudos abranjam essa relação quanto ao uso do fogo.
Os tipos de vegetações e a quantidade de pesquisas para as mesmas consistiu em $56,66 \%$ em Floresta Temperada, 36,66\% para Floresta Boreal e apenas $6,68 \%$ para Floresta Tropical. O efeito do fogo nessas tipologias florestais ocorreu de forma diversa, na Floresta tropical e boreal não verificou diferença significativa entre os efeitos do fogo, no entanto para a Floresta temperada os incêndios florestais o efeito foi negativo e positivo para as queimas controladas.

\section{Discussão}

Existe uma prospecção futura positiva quanto as pesquisas voltadas para os efeitos ocasionados aos microrganismos do solo em decorrência do uso do fogo, tendo em vista que a busca por parte dos pesquisadores em compreender a dinâmica do fogo e seu efeito nos diversos ecossistemas é notória, as informações obtidas nestes estudos podem contribuir no gerenciamento de florestas, como forma de evitar comprometer a composição e função das comunidades de fungos do solo, sendo eles cruciais aos serviços dos ecossistemas através de ciclagem de nutrientes e influenciar na produtividade da planta (Dooley e Treseder, 2012).

No EUA a silvicultura desenvolve um papel importante na economia. Desta forma para evitar prejuízo comercial oriundo dos incêndios florestais, se faz necessário adoção de medidas preventivas sobre o tema como por exemplo a queima prescrita usada para reduzir a quantidade de combustível em ecossistemas florestais (Kowal et al. 2013). A mesma vem sendo utilizada como ferramenta para restauração e conservação de ecossistemas, em alguns ecossistemas o uso do fogo resulta na melhoria quanto a riqueza de espécies, Oliver et al. (2015) em seu estudo sobre as recorrentes queimas prescritas em um ecossistema florestal no sudeste dos EUA observou que o manejo prescrito do fogo ao longo de vinte anos afeta minimamente a diversidade da comunidade fúngica do solo.

Desta forma embora a queima prescrita tenha se tornado uma ferramenta de manejo florestal cada vez mais utilizada em diversos ecossistemas no mundo, o que se tem conhecimento é que a queima prescrita consiste na utilização do fogo em condições controladas, sendo prevista em lei e utilizada na redução de material combustível com intuito de minimizar a extensão e a gravidade dos incêndios florestais, em contraste nos incêndios florestais que o fogo é sem controle e provocado pelas ações antrópicas ou naturais, onde se tem uma carga abundante de material combustível (Mittal et al., 2019).

As propriedades do solo podem sofrer alterações de curto, longo prazo ou permanentes, 
induzidas pelo uso do fogo, dependendo principalmente do tipo de propriedade, gravidade e frequência dos incêndios e condições climáticos pós queima. Hatten \& Zabowski (2010) afirmam que os incêndios florestais consomem mais da biomassa aérea e matéria orgânica, resultando em maior volatilização de nutrientes do que as queimas prescritas. Sendo isto atribuído parcialmente a um dos princípios básicos do manejo do fogo que é a intensidade, as queimas prescritas ocorrem sob condições que resultam em menor intensidade e severidade do fogo, ao contrário dos incêndios florestais que apresentam maior intensidade e severidade. Na figura 4 está esquematizado os efeitos diretos e indiretos do fogo em função da diversidade dos microrganismos.

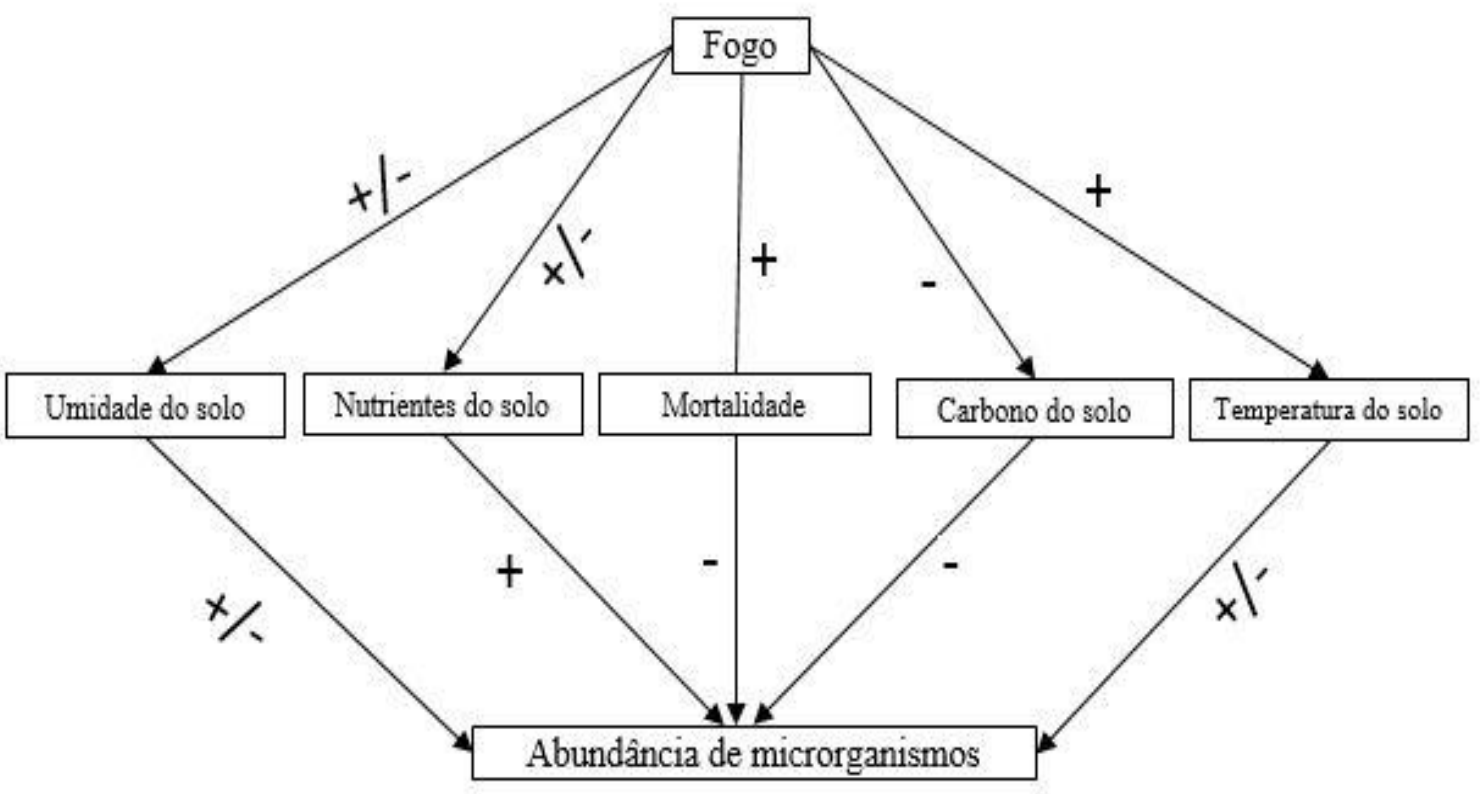

Figura 4. Esquema dos potenciais mecanismos diretos e indiretos do fogo. Em que (+) pode ou (-) diminuir a abundância dos microrganismos. Adaptado de Dooley e Treseder (2012).

O efeito imediato do fogo nos microrganismos de solo é a redução da biomassa que afeta a sobrevivência e a recolonização dos organismos do solo, outro efeito importante são os picos de altas temperaturas que o solo atinge o solo durante um incêndio florestal podendo ocasionar uma esterilização completa dos microrganismos. Os efeitos adversos na biota do solo podem ser devidos também a alguns poluentes orgânicos produzidos pelos processos de combustão. De fato, Kim et al. (2003) verificaram que os compostos tóxicos, tais como policloradas dibenzo-p-dioxinas (PCDDs), dibenzofuranos (PCDFs) e hidrocarbonetos aromáticos polinucleares (PAHs) são realmente liberados durante o incêndio e redistribuídos no solo.

As respostas fúngicas do solo ao fogo podem diferir da resposta da comunidade microbiana como um todo. Alguns fungos são tolerantes a solos ácidos e normalmente possuem maior abundância sobre os demais microrganismos em solos com baixo $\mathrm{pH}$, enquanto a abundância bacteriana no solo aumenta de baixo para alto pH (Bárcenas-Moreno et al., 2011; Rousk et al., 2010; Jörgen e Bengt, 2010). A deposição de cinzas após incêndios aumenta o pH do solo (Peay et al., 2009), podendo favorecer o crescimento de bactérias e resultar em declínios dos microrganismos fúngicos. Nas pesquisas realizadas sobre o efeito dos incêndios florestais nos microrganismos, constataram que os fungos podem ser mais sensíveis ao calor do que as bactérias (Pourreza et al., 2014), sugerindo assim que os fungos podem ser mais gravemente afetados pelo fogo do que a comunidade microbiana como um todo em alguns ecossistemas.

Ao determinar os regimes de fogo ideais, as características dos ecossistemas devem ser levadas em considerações como forma de garantir a estabilidade e a sustentabilidade do ecossistema a longo prazo. Por exemplo em sistemas que não são adaptados ao fogo, ou que ocorreu a exclusão do fogo por muito tempo, a ocorrência de incêndios frequentes pode reduzir significativamente a biomassa fúngica do solo (Dooley e Treseder, 2012).

Neste sentindo alguns trabalhos indicam que alguns fungos são favorecidos pelas condições de incêndios florestais, enquanto outros desaparecem, variando em função das características da vegetação (Harden et al., 2003; Peay et al., 2009; Jonsson et al., 
2003; Kajar et al., 2014). As consequências dos incêndios em alta intensidade em florestas temperadas diferem consideravelmente daqueles em florestas boreais, em sua pesquisa sobre os efeitos do fogo sobre os fungos em Florestas boreais, o pesquisador Dahlberg (2002) apontou que embora estas florestas possuam um número reduzido de espécies de plantas, existe uma alta diversidade fungos, em seu estudo ele obteve resultados positivos para esse tipo de vegetação, apontando que após o fogo se inicia uma sucessão dos microrganismos fúngicos, destacando também que várias centenas de organismos boreais são favorecidos após o uso do fogo, embora não seja dependentes dele, algumas espécies boreais de fungos que habitam madeira por exemplo teve um notável resistência ao calor.

A faia europeia (Fagus sylvatica L.) espécie comumente encontrada nas florestas temperadas possui um relevante valor econômico e ecológico, sendo esta altamente suscetível ao fogo. Pesquisas voltadas para esta espécie vem sendo realizadas e o que se tem conhecimento é que o tempo de mortalidade da faia pós-fogo depende da intensidade do fogo. Em que sua mortalidade pode ocorrer imediatamente após os incêndios de alta intensidade ou ser adiada após um incêndio de baixa intensidade (Treseder et al.; Conedera et al.; 2007; Ascoli et al., 2013).

Prakash et al. (2015) em sua pesquisa sobre a ecologia e diversidade de fungos da serapilheira durante a decomposição em estágio inicial em uma floresta tropical sazonal observou que alguns gêneros de fungos possuem adaptações que favorecem a sua sobrevivência em ecossistemas florestais propensos a incêndios florestais. As características dos ecossistemas devem ser levadas em consideração, quando a tomada de decisão acerca dos regimes de fogo ideais. Em sistemas que não possuem adaptação ao fogo ou que o uso foi excluído por muito tempo, a ocorrência de um incêndio pode promover a redução significativa da biomassa fúngica no solo, reduzir a quantidade de carbono no solo e alterar a disponibilidade de nutrientes, apontando que as propriedades do solo biótica e abiótica são sensíveis ao fogo pelo menos a curtos prazos (Dooley e Treseder, 2012; Dejene et al., 2017).

Conclusão

- Os mecanismos ou processos responsáveis pela diversidade de espécies de fungos após o uso do fogo tanto para incêndios como em queima prescrita permanecem desconhecidos.

- A padronização das metodologias é necessária para que se possa realizar comparações entre os estudos da mesma tipologia de vegetação.

- Pesquisas destinadas a avaliação dos aspectos positivos e negativos do fogo controlado em função dos microrganismos são fundamentais, tendo em vista que os usos da queima prescrita em alguns ecossistemas podem ser considerados essenciais para a conservação da diversidade.

\section{Referências}

Ascoli D, Daniele D, Valsechhi C, Conedera M, Giovanni B (2013) Post-fire restoration of beech stands in the Southern Alps by natural regeneration. Ecological Engineering, 54(1): 210-217. doi: 10.1016/j.ecoleng.2013.01.032

Bárcenas-Moreno G, Rousk J, Bååth E (2011) Fungal and bacterial recolonisation of acid and alkaline forest soils following artificial heat treatments. Soil Biol Biochem, 43(5): 1023-1033. doi: 10.1016/j.soilbio.2011.01.019

Benjamin TN, Smithb JE, Luomma DL, Hatten JA (2018) Recovery of ectomycorrhizal fungus communities fifteen years after fuels reduction treatments in ponderosa pine forests of the Blue Mountains, Oregon. Forest Ecology and Management, 422(1): 11-22. doi: 10.1016/j.foreco.2018.03.050

Cairney JWG, Bastias B (2007) Influences of fire on forest soil fungal communities. Can J For Res, 37(1): 207-215. doi: 10.1139/x06-190

Claridge AW, Trappe JM, Mills DJ, Debbie L (2009) Diversity and habitat relationships of hypogeous fungi. III. Factors influencing the occurrence of fire-adapted species. Mycological Research, 113(6-7): 792-801, doi: 10.1016/j.mycres.2009.02.014

Conedera M, Lucini L, Holdenrieder O (2007) Pilze als Pioniere nach Feuer. Wald und Holz, 88(11): 45-48.

Dahlberg A (2002) Effects of fire on ectomycorrhizal fungi in Fennoscandian boreal forests. Silva Fennica, 36(1): 69-80. doi: 10.14214/sf.551 
Dejene T, Oria-de-Rueda JA, Martín-Pinto $P$ (2017) Fungal community succession and sporocarp production following fire occurrence in Dry Afromontane forests of Ethiopia. Forest Ecology and Management, 398: 37-47. doi: 10.1016/j.foreco.2017.05.011

Demoling F, Nilsson L, Baath E (2008) Bacterial and fungal response to nitrogen fertilization in three coniferous forest soils. Soil Biol Biochem, 40(2): 370-379. doi: 10.1016/j.soilbio.2007.08.019

Dooley SR, Treseder KK (2012) The effect of fire on biomass microbial: a metaanalysis of field studies. Biogeochemistry, 109(1-3): 49-61. doi: 10.1007/s10533-0119633-8

Fuentes-Ramirez A, Barrientos M, Almonacid L, Arriagada-Escamilla C, Salas-Eljatib C (2018) Short-term response of soil microorganisms, nutrients and plant recovery in fire-affected Araucaria araucana forests. Applied Soil Ecology, 131(1): 99-106. doi: 10.1016/j.apsoil.2018.08.010

González-Vila FJ, Almendros G, Knicker H (2004) The effect of fire on soil organic matter: a review. Environ Int, v. 30(6): 855870, 2004.2 doi: 10.1016/j.envint.2004.02.003

Harden JW, Mack M, Veldhuis H, Gower ST (2003) Fire dynamics and implications for nitrogen cycling in boreal forests. $J$ Geophys Res, 108: 8223-8230. doi: 10.1029/2001JD000494

Hatten JA, Zabowski D (2010) Fire severity effects on soil organic matter from a ponderosa pine forest: a laboratory study. Int. J. Wildland Fire, 19(5): 613-623. doi: 10.1071/WF08048

Hawkes CV, Kivlin SN, Rocca JD, V. Huguet V, Thomsen MA, Suttle KB (2011) Fungal community responses to precipitation. Glob Change Biol, 17(4):
1637-1645. doi: $10.1111 / \mathrm{j} .1365-$ 2486.2010.02327.x

Jonsson L, Dahlberg A, Nilsson MC, Zackrisson O, Kårén O (2003) Ectomycorrhizal fungal communities in late-successional Swedish boreal forests, and their composition following wildfire. Molecular ecology, 8(2): 205-215. doi: 10.1046/j.1365-294x.1999.00553.x

Jörgen O, Bengt GJ (2010) Restoration fire and wood-inhabiting fungi in a Swedish Pinus sylvestris forest. Forest Ecology and Management. 259(10): 1971-1980. doi: 10.1016/j.foreco.2010.02.008

Kajar K, Frank B, Aki L, Egle K, Jukka P (2014) Recovery in fungal biomass is related to decrease in soil organic matter turnover time in a boreal fire chronosequence. Geoderma. 235: 74-82. doi: 10.1016/j.geoderma.2014.07.001

Kasischke E, Stocks B (2000) Fire, climate change and carbon cycling in the boreal forest. Springer, New York, 2000.

Kowal, V, Schmolke A, Rajapandian K, Douglas B (2013) Resource selection probability functions for gopher tortoise: providing a management tool application across the species' range. Environ. Manage. 53(3): 594-605. doi: 10.1007/s00267-0130210-x

Kim EJ, Oh JE, Chang YS (2003) Effects of forest fire on the level and distribution of PCDD/Fs and PAHs in soil. Sci Total Environ, 311(1-3): 177-189.

Miller JD, Safford HD, Crimmins M, Thode AE. (2009) Quantitative evidence for increasing forest fire severity in the Sierra Nevada and Southern Cascade Mountains, California and Nevada, USA. Ecosystems, 12(1): 16-32. doi: 10.1007/s10021-0089201-9

Mittal D, Shukla R, Verma S, Sagar A, Verma KS, Pandey A, Negi YS, Saini RV, 
Saini AK (2019) Fire in pine grown regions of Himalayas depletes cultivable plant growth promoting beneficial microbes in the soil. Appl. Soil Ecol. 139(1): 117-124, doi: 10.1016/j.apsoil.2019.03.020

Oliver AK, Callaham JMA, Jumpponen A (2015) Soil fungal communities respond compositionally to recurring frequente prescribed burning in a managed southeastern US forest ecosystem. For. Ecol. Manage, 345(9): 1-9. doi: 10.1016/j.foreco.2015.02.020

Peay KG, Garbelotto M, Bruns TD (2009) Spore heat resistance plays an important role in disturbance-mediated assemblage shift of ectomycorrhizal fungi colonizing Pinus muricata seedlings. J Ecol, 97(10): 537-547. doi: 10.1111/j.14610248.2007.01035.x

Pechony O, Shindell, DT (2010) Driving forces of global wildfires over the past millennium and the forthcoming century. PNAS 107, 107(45): 19167-19170. doi: 10.1073/pnas. 1003669107

Pourreza M, Hosseini SM, Sinegani AAS, Matinizadeh, M (2014) Soil microbial activity in response to fire severity in Zagros oak (Quercus brantii Lindl.) forests, Iran, after one year. Geoderma, 213(1): 95102. doi: 10.1016/j.geoderma.2013.07.024

Prakash CP, Thirumalai E, Rajulu G, Thirunavukkarasu N (2015) Ecology and diversity of leaf litter fungi during earlystage decomposition in a seasonally dry tropical forest. Fungal Ecology, 17(1): 103113. doi: 10.1016/j.funeco.2015.05.004

Rousk J, Bååth E, Brookes PC, Lauber CL, Lozupone C, Caporaso JG, Knight R, Fierer $N$ (2010) Soil bacterial and fungal communities across a $\mathrm{pH}$ gradient in an arable soil. ISME J, 4(10): 1340-1351. doi: 10.1038/ismej.2010.58

Silvana L, Nouhra E, Goto BT, Berbara RL, Urcelay C (2014) Effects of fire on arbuscular mycorrhizal fungi in the Mountain Chaco Forest. Forest Ecology and Management, 315(1): 86-94. doi: 10.1016/j.foreco.2013.12.027

Treseder KK, Mack MC, Cross A (2004) Relationships among fires, fungi, and soil dynamics in alaskan boreal forests. Ecological applications, 13(1): 1826-1838. doi: 10.1890/03-5133 